Post-print version of:

Publisher: Elsevier

Journal paper: International Journal of Fatigue 2012, 45 71-81

Title: Surface and subsurface rolling contact fatigue characteristic depths and proposal of stress indexes

Authors: C. Santus, M. Beghini, I. Bartilotta, M. Facchini

Creative Commons Attribution Non-Commercial No Derivatives License

$$
\text { (a) }(\mathbb{Q} \Theta \Theta
$$

DOI Link: https://doi.org/10.1016/j.ijfatigue.2012.06.012 


\title{
Surface and subsurface rolling contact fatigue characteristic depths and proposal of stress indexes
}

\author{
C. Santus ${ }^{\text {a* }}$ M. Beghini ${ }^{\mathrm{a}}$, I. Bartilotta $^{\mathrm{a}}$, M. Facchini ${ }^{\mathrm{b}}$
}

a Dipartimento di Ingegneria, Meccanica, Nucleare e della Produzione, Università di Pisa. Largo Lucio Lazzarino n.2, 56126 Pisa, Italy.

b AVIO Propulsione Aerospaziale S.p.A. Via I Maggio n.99, Rivalta di Torino (TO) - 20097 - Italy.

\begin{abstract}
The rolling contact fatigue is distinguished into subsurface initiated (spalling and case crushing) and surface initiated (pitting and micropitting). A characteristic depth was identified for each of these mechanism. The characteristic depth of the case crushing is the hardening depth, while for the spalling it is the maximum cyclic shear stress depth. The pitting depth is the size of the crack for which the mode I stress intensity factor range, due to the fluid pressurization, is higher than the threshold. This depth can be similar to the micropitting depth, in the order of $10 \mu \mathrm{m}$, for heavily loaded small radius contacts. Rolling contact fatigue cyclic shear stress indexes are then defined on the basis of the characteristic depths, and they identify the load intensity of each rolling contact fatigue mechanism. The characteristic depths and the stress index approach can be used to relate specific tests to component design, without any size effect misinterpretation.
\end{abstract}

Keywords: Rolling contact fatigue. Case crushing. Spalling. Pitting. Micropitting. Characteristic depths.

${ }^{*}$ Corresponding author: Ciro Santus Ph. +39 (0)50 2218007 Fax +39 (0)50 2218065

email: ciro.santus@ing. unipi.it 


\section{Notation}

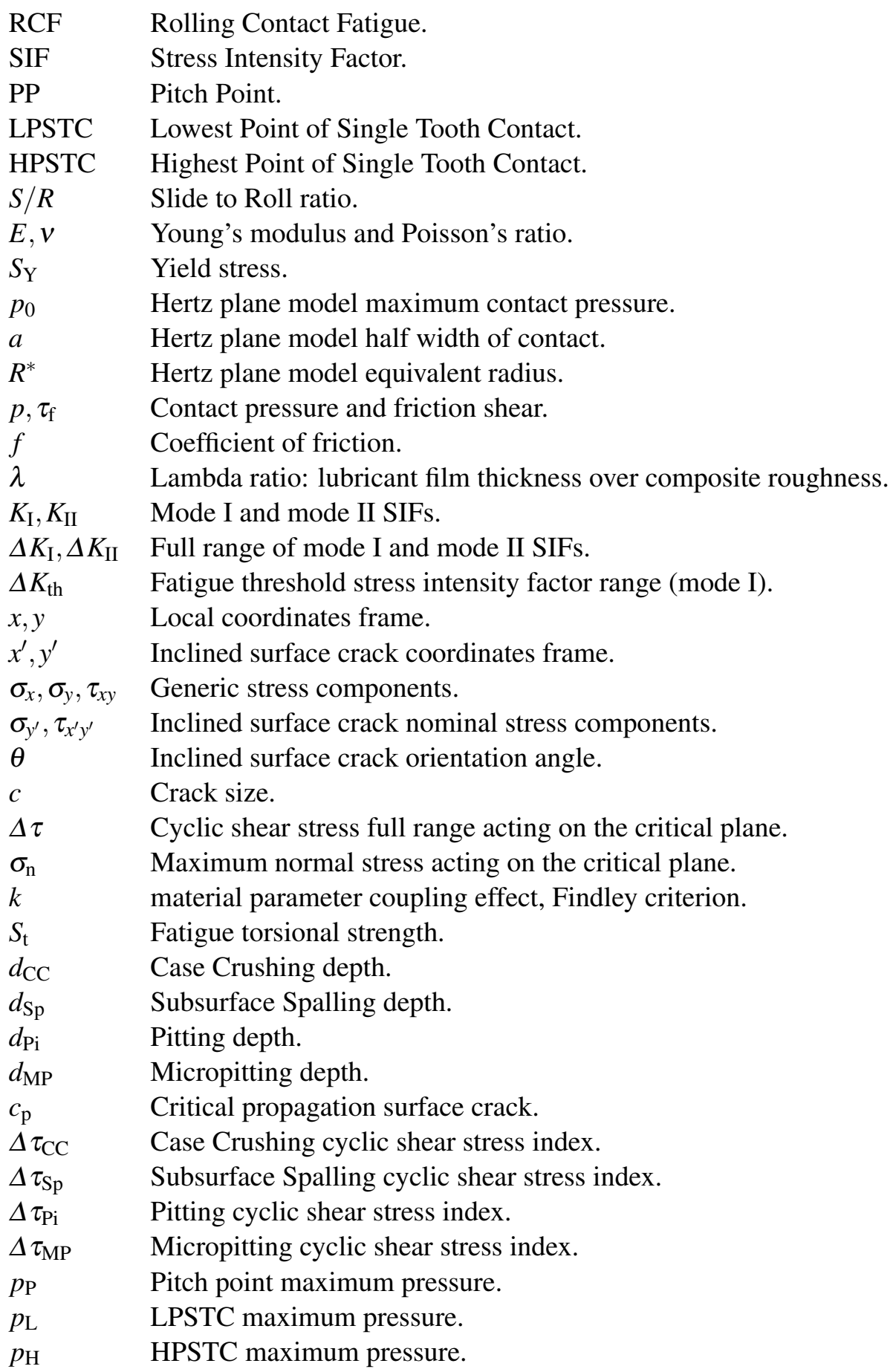




\section{Introduction}

The Rolling Contact Fatigue (RCF) is a typical failure mode for components loaded by repeated heavy Hertzian contact pressure, such as cams, rolling bearings and gears. The RCF is the ultimate damage when scuffing is avoided by means of proper lubrication and other fatigue or static failure mechanisms are prevented by a safe design. Several authors have faced the RCF phenomena with experimental or modeling approaches. Recently, a comprehensive review paper by Olver [1] highlighted the differences between the RCF and the "classic" fatigue, starting from a contact free surface (for instance at the root of a notch) that is typically caused by a tensile stress field, with proportional components. On the contrary, the RCF stress field is compressive, multiaxial with not proportional components and very high gradient. Moreover, Olver [1] pointed out the differences between the RCF in very hard steels, such as those employed in bearings and gears, compared to that experienced by relatively lower yield stress steels, such as rail track in contact with train wheel. The softer materials go through a plastic shakedown, usually preceded by a significant ratcheting phase, while the harder materials do not experience widespread plasticity or just elastic shakedown during the initial cycles $[2,3]$.

The RCF a broad expression that embraces different mechanisms. Unfortunately, the RCF nomenclature is not standardized. Sometimes, pitting and spalling are considered as synonyms, the difference would only be that spalling is the evolution phase of pitting [4], and micropitting is alternatively termed either as surface distress, peeling, gray staining or even frosting $[1,4,5,6]$. In the present paper the nomenclature followed is that initially introduced by Littmann [7] and also proposed by Olver [1]. Four RCF mechanisms are distinguished:

- Case Crushing: subcase fatigue, experienced by surface hardened components;

- Spalling: subsurface originated rolling contact fatigue;

- Pitting: surface originated rolling contact fatigue;

- Micropitting: shallow pitting.

This nomenclature is the most descriptive of the physical evolution of each damage mechanism. According to this classification, spalling and pitting are not different stages of the same phenomenon but different damage mechanisms, distinguished by the position where the crack initiates.

When the fatigue crack nucleates at the surface (Pitting and Micropitting) the RCF interacts with tribological phenomena. The local loads promoting the surface cracks strongly depend on friction, surface roughness and lubricant fluid properties. All these issues are difficult to be reliably modeled, moreover, several mechanisms play important roles at different conditions, while any model tends to be focused mainly on one mechanism. A complete predictive model for RCF does not exist at the present in spite of the large amount of experimental results and the availability of computational resources.

After a literature review, the present paper introduces the characteristic depths for each RCF mechanism, that define the the process zone sizes. These depths allow to identify where the cyclic stresses have to be evaluated, to introduce a significant damaging stress index for each RCF mechanism. A remarkable conclusion of the proposed investigation is that the characteristic depth of the Pitting can be as small as the Micropitting depth. This is basically in agreement with Ding et al. [8,9], they defined Spalling as subsurface initiated and investigated the depth size, while they used the term Pitting to define the formation of craters initiated from the surface, even if very shallow. In the present paper, however, an important distinction of the pitting is introduced. The pitting surface crack propagation can be supported by the pressurization effect of the lubricating fluid or, on the contrary, the lubrication fluid pressurization can be ineffective and the surface pits are the result of material detachment after surface cracking. This latter mechanism typically has a low depth, hence it is Micropitting, while the fluid pressurization pitting mechanism has a depth that depends on several factors, that are investigated in the paper. This depth can be either quite small, same size of Micropitting, or larger.

The stress indexes and the characteristic depths can be used to relate laboratory test results, such as disc tests, 
to the design of components, such as gears or other contact loaded parts, with the same depth sizes. Moreover, the characteristic depths can suggest the proper penetration of any surface treatment designed to increase the RCF strength.

\section{Different factors promoting either surface or subsurface initiation}

As suggested by the adopted nomenclature, the first step to characterize the RCF damage phenomena is to identify in what conditions cracks initiate either from the surface or below the surface. Subsurface spalling would be expected to be the predominant mechanism, since the shear stress amplitude is highest at a certain position below the surface (this depth is investigated in the following). However, it is well known that gear teeth and bearings mainly experience surface pitting instaed of subsurface spalling [4]. Fajdiga et al. [10] and Glodež et al. [11] reported that in high precision mechanical components, with fine surface finish and under good lubrication conditions, the fatigue crack usually initiates under the contacting surface, while surface initiated pitting is observed in gears with rough (as ground) surfaces and poor lubrication. Nélias et al. [12,13] investigated surface and subsurface damage initiations, by testing polished and as ground discs, under different contact conditions, and by accurately examining the surface checking for any subsurface initiated defect with ultrasonic echography. Lubricated polished specimen contacts had the $\lambda$ ratio (lubricant film thickness over composite roughness) larger than unity. On the contrary, as ground unpolished specimens had $\lambda<1$. The polished specimens never showed surface initiation, while the unpolished specimens always showed micropitting and/or microcracking evolving into surface pitting for large contact pressure and sliding. Summarizing, the surface originated RCF is expected when roughness asperities are in contact, while the subsurface originated RCF occurs when the contact is well supported by the lubrication.

The surface initiation dependency on friction and surface roughness was also reported in the Failure Atlas for Hertz Contact Machine Elements by Tallian [5], but it was also introduced the important role of the material defectiveness. The presence of subsurface brittle volumes or porosity promote subsurface initiation, while surface defects such as: finishing marks, grinding damage, near surface decarburization or matrix damage, promote surface initiation. The quality of the high strength steels for bearings and gears, however, is continuously improved nowadays and composition, heat treatments and surface finish are accurately controlled, hence the defectiveness influence is less significant to drive the initiation site. The surface treatment can also be very influential. Gao [14] showed that specimens tended to experience subsurface initiation after shot peening, while unpeened specimens showed surface initiation, apparently because of the residual stress and the work hardening in the peened layer. In agreement with the previous, Cavallaro et al. [15] also reported a strong dependence of the initiation site from the treatment of the surface and its conditions. They found that the shot peening treatment on discs slightly improves the fatigue limit but produces subsurface crack initiation and prevents surface initiation.

\section{Subsurface spalling and case crushing}

The very initiation of subsurface spalling, in high strength steels, is the formation of "butterflies" and subsequent cracks at porosity or at small non-metallic inclusions (such as alumina, carbides, etc.) [2, 12, 16, 17] even with very accurate controlled structure. Chen et al. [18] also detected the subsurface initiation, and then the crack was observed to propagate toward the surface or, more precisely, propagated and branched. A reason for controversy in the literature is whether a subsurface crack can propagate under mode II, after initiation. Indeed, a subsurface initiated crack can not experience positive mode I Stress Intensity Factor (SIF) $K_{\mathrm{I}}$, during the contact loading, as the stress field is purely compressive. The mode I SIF remains null because the crack faces are in contact. Under these conditions, any crack propagation can be explained only after assuming an effective mode II propagation (or mode II combined with mode III). The mode II propagation was supported by Fleming and Suh [19], Keer and Bryant [20], O'regan et al. [21], Kaneta [22] et al., Blake and Cheng [23], and 
more recently by Choi and Liu [24, 25, 26]. In contrast, Ding et al. [8, 9, 27, 28] clearly distinguished these two different phases. The subsurface crack nucleates from a material point defect, that experiences high shear stress amplitude, but this does not mean that the further propagation is mode II. They supported the subsurface shear stress initiation plus mode II propagation just for the first stage, while the further stage is multiple cracks linking up and then ligament collapse. However, this is in apparent contradiction to the just mentioned paper by Chen et al. [18], where propagation and branching were observed. The papers by Fajdiga et al. [10] and Glodež et al. [29, 30] reported a successful comparison between the simulated subsurface initiated crack and the the observed final crater, supporting the subsurface propagation theory. The considered driving force was the equivalent SIF (also proposed by Panasyuk et al. [31]) defined on the basis of the energy release rate and calculated by the virtual crack extension with a finite element model. The interpretation of Glodež and Fajdiga et al. was questioned by Ding and Gear [9] reporting that the equivalent SIF were too low to produce crack growth. The papers by Raje et al. [32, 33] were basically in agreement with the theory by Ding et al. [9] supporting the multiple cracks linking up hypothesis. They developed a discrete material model, in order to reproduce the mesoscale of the a polycrystalline material, and a population of cracks initiated, instead of a single crack. After initiation, these cracks interact and link up. Raje et al. [33] compared their multiple cracking model with the subsurface cracking reported by Chen et al. [18] and found a reasonable agreement in terms of the final crater shape. Maybe, all the three propagation mechanisms can compete: multiple cracks linking up, mode II propagation, and branching. One mechanism can prevail on the others for a specific combination of material, residual stresses, and contact load. However, if a fail safe approach is aimed, the first stage of diffused subsurface microcracking is of primarily interest, rather than the subsequent and the final phases of the damage.

The surface hardness is usually increased in gear steels by means of a case hardening treatment. The case hardening depth can be technologically controlled but it is usually not larger than $1.0 \mathrm{~mm}$. If the hardness depth is not large enough, with respect to the extension of the contact highly stressed region, the more brittle case-bulk material interface experiences high cyclic shear stress and then the hardened case can delaminate $[4,5]$. The case hardening can be basically considered a mechanism similar to the subsurface spalling, except that the location of the damage is driven by the material discontinuity. The case hardening can introduce a hardness gradient, instead of a definite case-bulk interface [34]. In such a situation, Leng et al. [35, 36] proposed a damage index defined as the maximum ratio between shear stress and local hardness. They observed that the subsurface damage initiated from a group of cracks, instead of a single crack, at the depth where the maximum shear stress to hardness ratio was highest. A size effect is evident here. If the contact size is large, so it is the depth of high stress below the surface, consequently the depth of the hardening should be adequate to avoid high stress amplitude at the weak hardened to bulk layer interface.

\section{Pitting and micropitting}

The first step of the surface RCF is the generation of shallow microcracks, with a surface angle of $20^{\circ}-30^{\circ}$ as shown in the Fig.1. The orientation of these microcracks is related to the friction traction, as reported by many researchers, e.g. by Olver et al. [1,37]. Indeed, the microcracks appear with opposite orientations, across the pitch point in gear tooth flanks, where the sliding direction and the friction traction reverse, Fig.2.

The inclined surface crack can continue propagating by following the same orientation of the previous microcrack which formed the micropit. This second stage of crack growth can evolve into deeper pitting, Fig.4. It is questionable whether this second stage crack initiates after the formation of the micropit, or the inclined crack propagation process is unique and just a small portion of material detaches at a certain depth, creating the micropit, but leaving the path for a further growth. According to Glodež et al. [38] and Fajdiga and Sraml [39], this latter hypothesis is more likely, since the next stage crack has the same morphology, and the same orientation, of the previous stage. An experimental evidence of micropitting to pitting evolution is also reported by Boniardi et al. [34]. They found the typical $10 \mu \mathrm{m}$ micropitting depth, but they showed that the surface microcrack re-initiates from the bottom of the micropitting crater, since the crack orientation was different after 


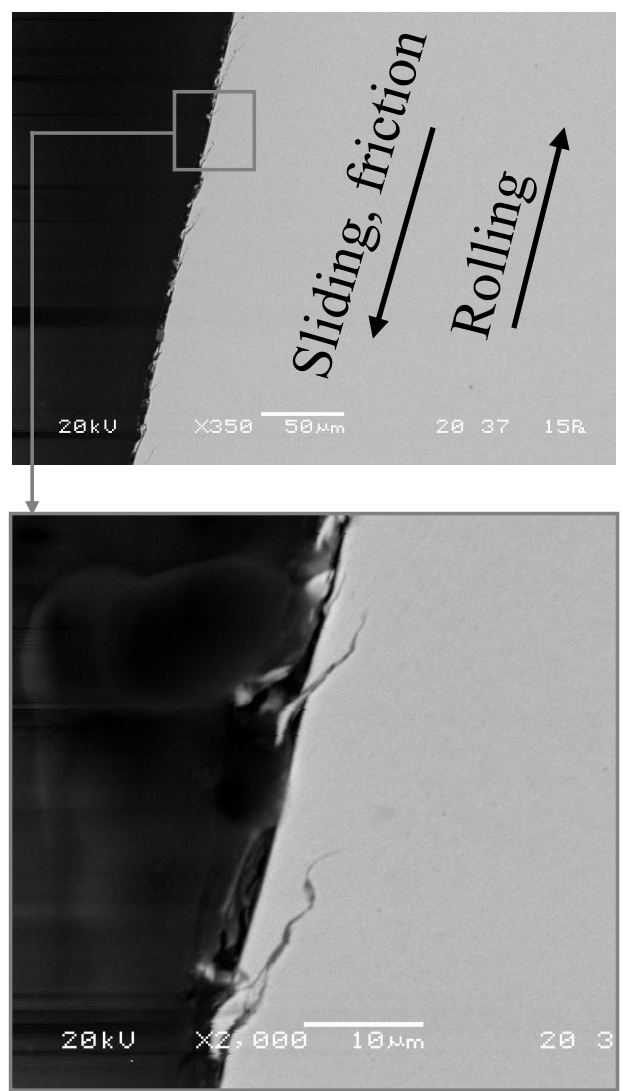

Figure 1: Microcracks evidence in a dedendum driver gear tooth. Typical shallow angle cracks, opposite to the shear stress direction.

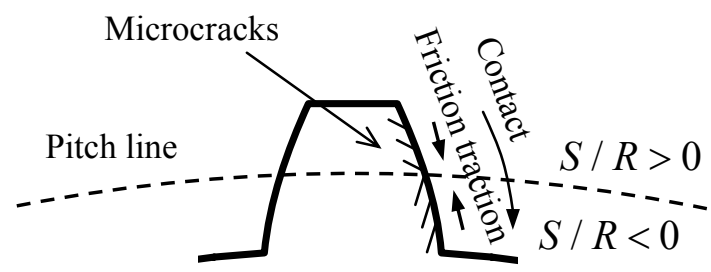

(a)

Driven gear tooth

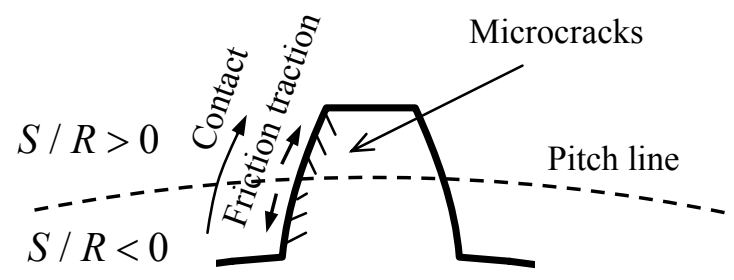

(b)

Driver gear tooth

Figure 2: Friction traction directions acting on the gear tooth flanks: (a) driven gear, (b) driver gear.

micropitting. After microcracking, the micropit is the consequence of the detachment of a material fragment produced when the microcrack has reached a critical size, merely forming a (micro) cantilever structure, Fig.3, 
and the depth of the detached fragment has the typical dimension of $10 \mu \mathrm{m}$.
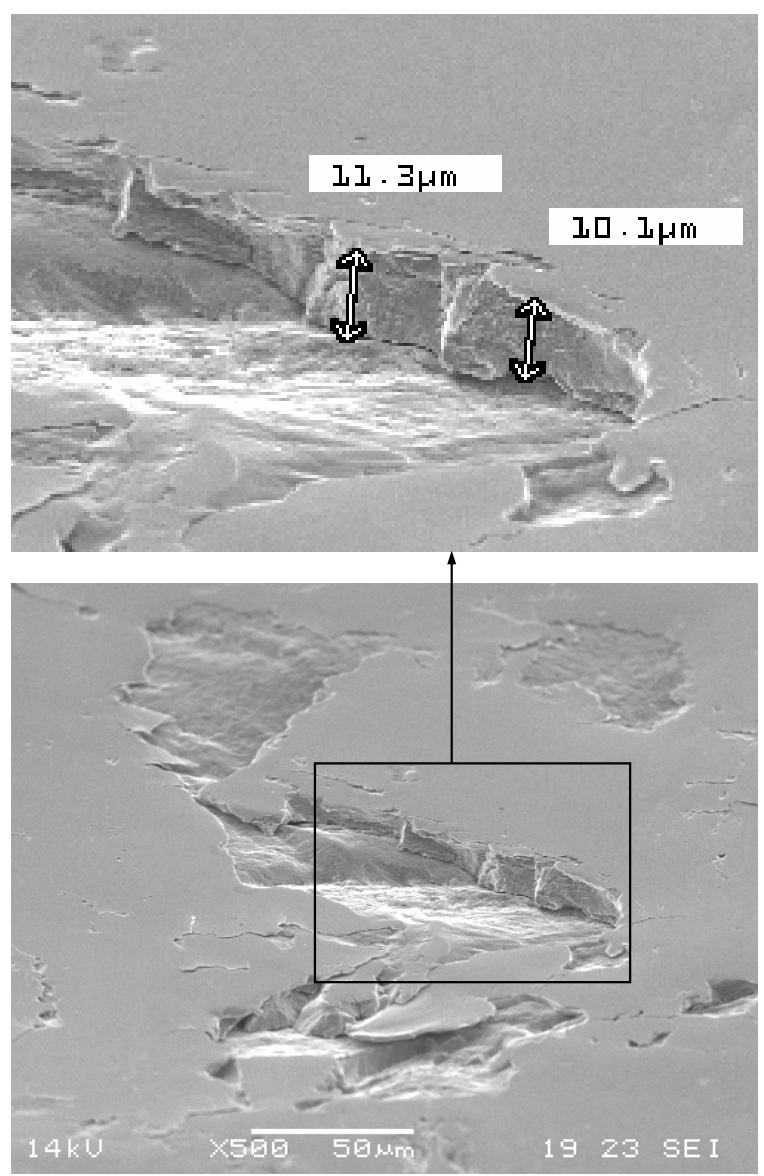

Figure 3: Experimental evidence of the typical micropitting depth.
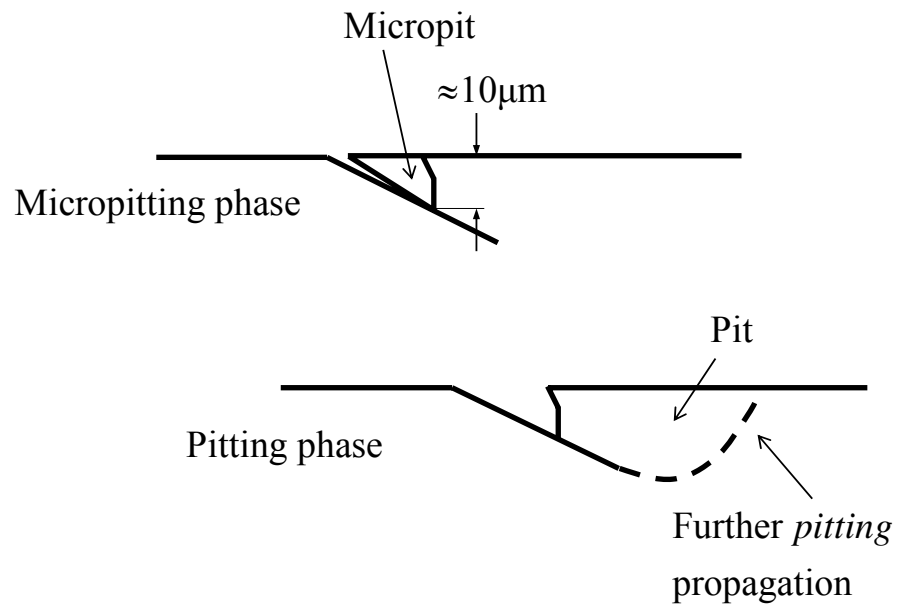

Figure 4: Inclined crack leading to pitting continuing from the previously formed micropit crack.

After these evidences, it follows that pitting implies a preliminary micropitting phase, however, it is still controversial if the micropitting inevitably evolves into pitting and in what conditions is to be expected just micropitting instead of pitting after micropitting. According to Tallian [5], there is evidence that the microcracking that produces micropitting does not automatically lead to a widespread pitting. In order to try to 
explain this evidence Tallian introduced the "quiescent" layer $[5,6]$. The microcracks fail to propagate when there is a depth range between the microcracks and the high Hertz shear stress zone, in which the cyclic stress is not high enough to drive the cracks. The quiescent layer concept was also supported by Miller et al. [40], resumed by Blake and Cheng [23] and by Donzella and Petrogalli [41]. Glodež et al. [30] also showed a low stress layer between the very near surface (roughness field) and below the surface. The quiescent layer concept is reconsidered in the present paper, on the basis of the depth of propagation surface crack, rather than on stress layer depth.

Nélias et al. [12] observed micropitting for all as ground specimens, as reported above, even without sliding (so without preliminarily microcracking). The micropitting appears just if the lubrication parameter $\lambda$ ratio is smaller than unity and it can be found especially along grinding marks, or on the top of longitudinal roughness of large wavelength. A likely explanation of this apparent micropitting / microcracking distinction is that no sliding condition at the asperity scale is not possible. Even macroscopic pure rolling generates some sliding, presumably with orientation reversal during the contact movement. In other words, the micropitting and microcracking are two different mechanisms when there is no macroscopic sliding to initiate microcracks. However, the surface microcracks initiated under sliding produce micropitting usually wider and deeper than that observed under pure rolling.

After a surface crack has initiated, the lubricating fluid can fill the open volume of the crack, and be pressurized while the contact is over the crack mouth. This well known mechanism is referred as "pressurization" or "fluid pumping". In the comprehensive paper by Bower [42] two phases are distinguished: the pressurization and the entrapment of the fluid when the crack turns closed from the top at a certain stage of the contact transit. The pressurized fluid produces a strong separating action on the edges of the crack, because the intensity of the fluid pressure is equal (or at least assumed equal) to the contact pressure between the mating surfaces, that can be even higher than $1000-1500 \mathrm{MPa}$. The crack faces are pulled apart and an opening mode I cycle is generated due to the pressurization, on the contrary, the surface crack would just remain closed, because of the compressive contact load. The fatigue crack propagation is forced by this positive mode I cycle. Way [43] was the first who obtained an experimental evidence of fluid pressurization enhanced pitting. After this initial experimental work, the pressurization mechanism was investigated (both experimentally and numerically) in many other papers [34, 37, 42, 44, 45, 46, 47].

The fluid pressurization can only occur if the Slide to Roll ratio $(S / R)$ is negative, i.e. if the sliding direction is opposite with respect to the rolling speed, otherwise the surface shear traction forces the crack mouth to remain closed, while the contact is approaching, and the lubricating fluid can not enter the crack $[42,45,48]$. During the gear meshing, the $S / R$ is negative at the dedendum both for the driven and the driver wheel teeth, Fig.2, or on the follower disc in a (twin) discs laboratory testing. The fluid pressurization was ever correlated with the experimental evidence that the surface pitting is usually on the dedendum tooth flank as reported in the Refs.[1, 34, 44, 49] and evident in the Fig.5.

Murakami et al. [47] investigated the $S / R$ effect with a discs testing equipment. They confirmed that the microcracks initiate because of the shear stress, indeed the crack orientation was related to the sliding speed. After microcracks investigation, their tests were continued with reversed direction of sliding, then it was evident that the microcracks evolve into pitting only if assisted by the pressurization mechanism.

\section{Characteristic depths and cyclic shear stress indexes}

The RCF is a evident example of multiaxial fatigue problem because the highly stressed region experiences more than one single stress component fluctuating during time. RCF is multiaxial non proportional and the stress principal direction orientation changes during time, both at the surface and at subsurface. There are many multiaxial fatigue criteria available in the literature. Among them the critical plane methods are usually applied to non proportional loading. Any critical plane method assumes a damage criterion, that usually is a combination of stress components. The plane that experiences the maximum value of that criterion is the critical plane. The Findley critical plane is the most common and representative of all the critical plane 


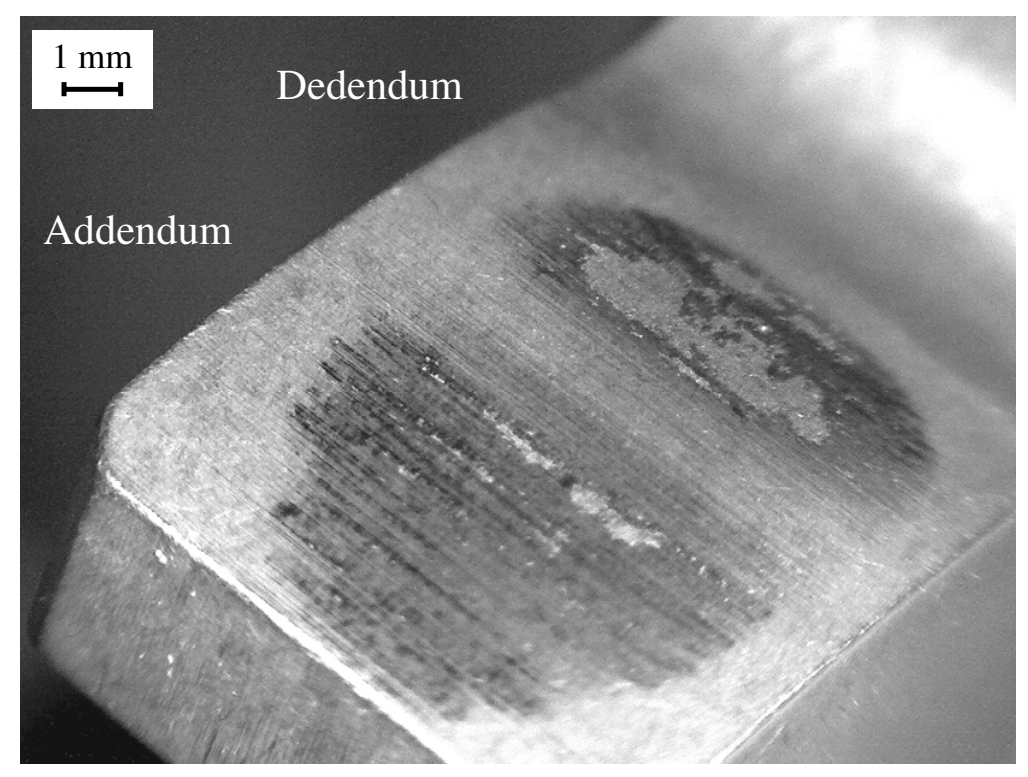

Figure 5: Evidence of pitting mainly at the gear tooth dedendum flank.

methods [50], Eq.1. The Findley criterion is the cyclic shear stress plus the tensile normal stress as a further detrimental effect.

$$
\frac{\Delta \tau}{2}+k \sigma_{\mathrm{n}} \leq S_{\mathrm{t}}
$$

$\Delta \tau$ is the cyclic shear stress on a generic plane, $k$ is the material coupling effect parameter, $\sigma_{\mathrm{n}}$ is the maximum (during time) normal stress acting on the same plane that experiences $\Delta \tau$, and $S_{\mathrm{t}}$ is the material torsional fatigue strength (easily found experimentally). In the RCF problem the stress state is always compressive at any point and any time, before the onset of a crack. The maximum value of $\sigma_{\mathrm{n}}$ is zero when the contact is away, while it is negative during the contact transit. The term $k \sigma_{\mathrm{n}}$ just vanishes in the Eq.1, hence the criterion reduces to the $\Delta \tau$ cyclic shear stress. The Findley method was also implemented by Evans et al. [51] by performing a deterministic analysis of the surface roughness in contact, confirming the cyclic shear based damage of the rolling contact fatigue. Also the well known and proven Lundberg-Palmgreen [52, 53] theory postulated the cyclic shear stress as the cause of the RCF damage and proposed a $\Delta \tau$ stress index.

The stress index approach is the identification of the most important load characteristic for a specific mechanism of failure. The stress index is a measure of how severe is that loading to be compared with an allowable stress that is a material property and that can be obtained with specific tests. The stress indexes proposed in the present paper are cyclic shear stresses at the critical plane, for each RCF mechanism, being the fatigue loading compressive and multiaxial. The RCF stress state is high gradient, as mentioned above, hence the cyclic shear stress is not uniform. The gradient of the cyclic shear stress is along the depth coordinate only. In RCF the surface contact stresses, and the subsurface high gradient distribution, is traveling, instead of being repeated on a fixed point (such as in a notched geometry), hence any point across the surface experience the same stress history. A key issue to define the proposed stress indexes is to identify the depth where any mechanism take place. As a consequence, the definition of the stress indexes is inherently related to the identification of the RCF mechanism characteristic depths.

\subsection{Case crushing}

The search of the critical plane orientation can be easily performed numerically at the surface and at any location in depth. The inclination angle of the cyclic shear stress critical plane changes with the depth. This plane orientation reduces to be almost parallel to the surface, at a depth similar to the contact width or higher, 
regardless the coefficient of friction. This plane inclination is also coincident with the case to bulk interface for the surface hardened components. The natural definition of the Case Crushing cyclic shear stress, $\Delta \tau_{\mathrm{CC}}$, is the range of the shear stress $\tau_{x y}$ where $x, y$ are the surface longitudinal and perpendicular directions respectively, at the hardening depth, Eq.2. This depth is consistently defined as the Case Crushing depth $d_{\mathrm{CC}}$, Fig.6.

$$
\Delta \tau_{\mathrm{CC}}=\left\{\max \left(\tau_{x y}\right)-\min \left(\tau_{x y}\right)\right\}_{\mathrm{depth}=d_{\mathrm{CC}}}
$$

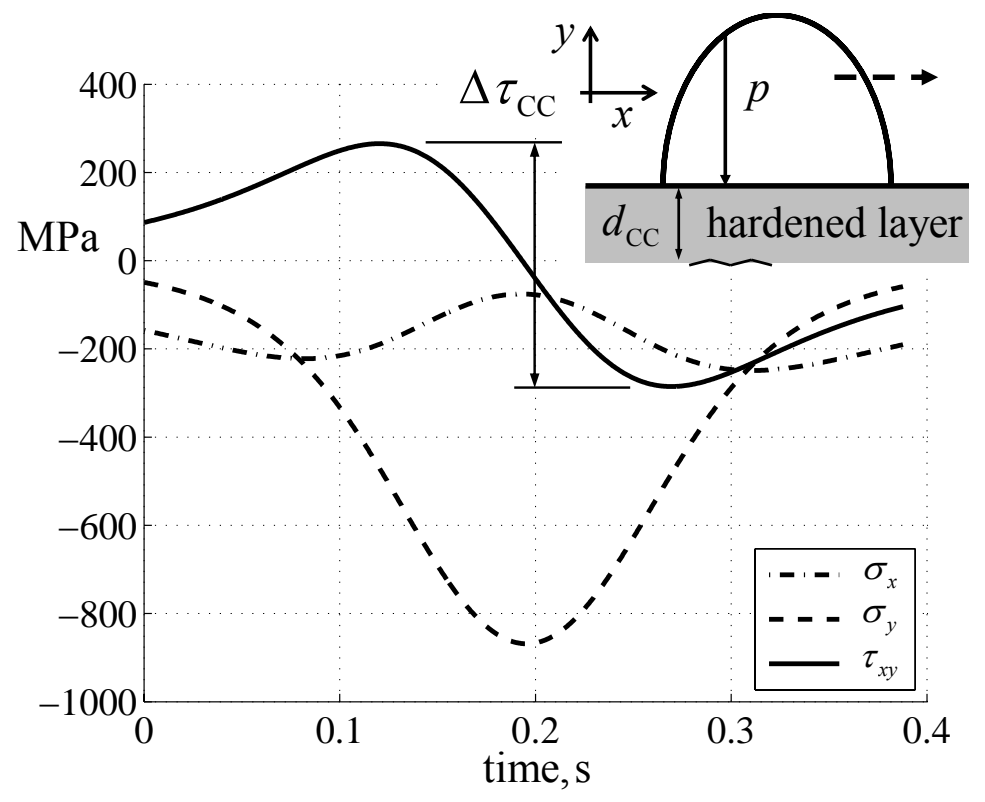

Figure 6: Case Crushing cyclic shear stress index definition.

\subsection{Subsurface spalling}

Similarly to the case crushing, the subsurface critical plane that experiences the maximum cyclic shear stress range is parallel to the surface. The evidence of horizontal orientation initial subsurface spalling crack was reported by many researchers, e.g. in the paper by Ding and Gear [9]. Indeed, the subsurface initial crack is usually modeled as horizontally oriented, e.g. by Glodež et al. [30] and by Raje et al. [32, 33]. The index here proposed to characterize the subsurface spalling damage is again the shear stress range $\Delta \tau_{x y}$, evaluated at the depth where the cyclic shear stress range is maximum, Eq.3, Fig.7.

$$
\Delta \tau_{\mathrm{Sp}}=\max _{\text {depth }}\left\{\max \left(\tau_{x y}\right)-\min \left(\tau_{x y}\right)\right\}
$$

This depth is here defined as the spalling characteristic depth $d_{\mathrm{Sp}}$ and can be found for any contact pressure distribution and pressure history, at least numerically. According to the plane contact Hertz model, without friction, the depth $d_{\mathrm{Sp}}$ is 0.5 times the half width of contact $a$, and this depth slightly changes for small values of the coefficient of friction. Moreover, $\Delta \tau_{\mathrm{Sp}}$ is equal to half the maximum contact pressure $p_{0}$, on the Hertz model basis.

\subsection{Micropitting}

The typical depth of micropitting is approximately $10 \mu \mathrm{m}$, as evident in the Fig. 3 and also reported elsewhere in the literature, from different experimental activities $[1,12,54]$. This depth is here defined as the micropitting 


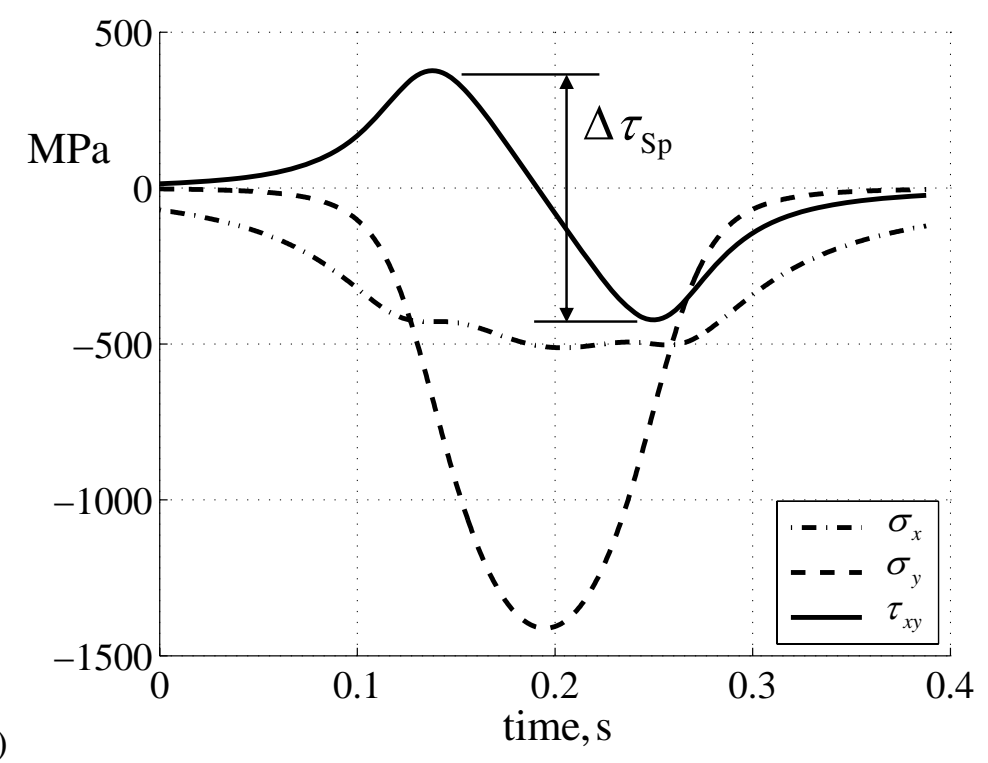

(a)

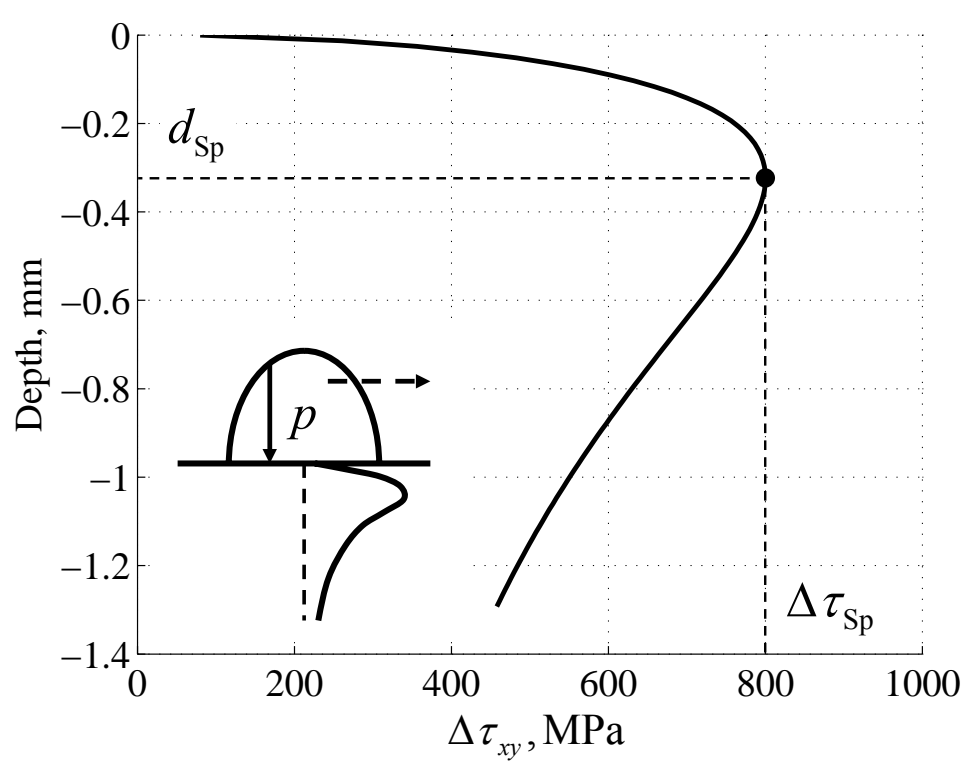

Figure 7: (a) Subsurface spalling cyclic shear stress definition. (b) Subsurface spalling characteristic depth definition.

characteristic depth $d_{\mathrm{MP}}=10 \mu \mathrm{m}$. The critical plane orientation and the cyclic shear stress acting on that plane were obtained at the surface and at lower positions up to the typical micropitting depth $d_{\mathrm{MP}}$. The proposed micropitting stress index is defined as the average cyclic shear stress, on the critical planes, from the surface to the $d_{\mathrm{MP}}$ depth:

$$
\Delta \tau_{\mathrm{MP}}=\frac{1}{d_{\mathrm{MP}}} \int_{0}^{d_{\mathrm{MP}}} \Delta \tau(y) \mathrm{d} y
$$

where $\Delta \tau(y)$ is the cyclic shear stress experienced on the critical plane at any depth $y$.

Assuming a typical friction factor value $f=0.05$, the average micropitting critical plane orientation angle is $20^{\circ}-30^{\circ}$, Fig.8, and this is in excellent agreement with the microcracking evidence, Fig.1. By introducing the opposite value for the friction factor, simulating opposite sliding, the orientation of the critical plane obviously reverses in agreement with the different orientation of microcracks between addendum and dedendum in gears, 
Fig.2.

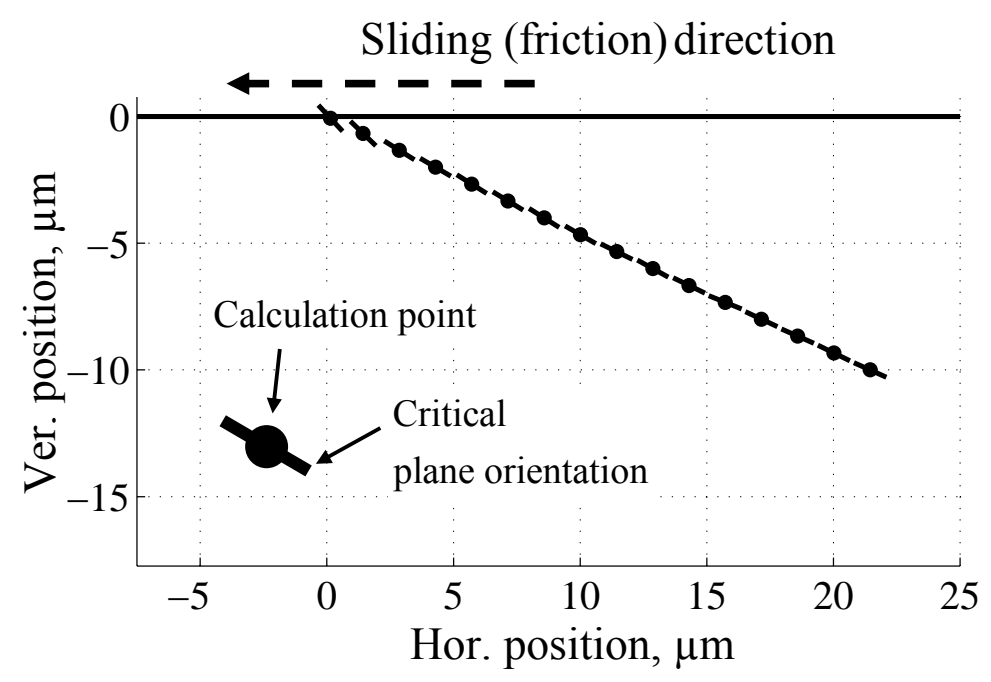

Figure 8: Critical plane orientation, from the surface to the micropitting depth.

\subsection{Pitting with the lubricating fluid pressurization}

The mode I and mode II SIFs generated by the surface contact with the pressurization mechanism can be found with different techniques [55]. The results reported in the present paper were obtained by means of a numerical procedure based on the Weight Function technique here briefly described. The surface load (such as the plane Hertz pressure and proportional shear traction) can be divided in a sequence of uniformly loaded cells for which the stress distribution solution is known in closed form at any point in the half space. The superimposition is then applied and the stress without the crack (nominal stress) is obtained. The crack SIFs were then calculated as integration of these nominal stresses with a the weight function as kernel. The matrix weight function proposed by Beghini et al. [56, 57, 58] was used for this integration. The effect of the pressurization was straightforwardly introduced by adding the pressure intensity, of the lubricating fluid inside the crack, to the nominal stress. The detailed explanation of this numerical technique can be found in the paper by Beghini and Santus [59] where the method was verified with literature data and with a finite element model. The mode I SIF was calculated at different stages during the contact transit over the crack, and the range $\Delta K_{\mathrm{I}}$ was obtained. This calculation was performed at different sizes of a surface inclined microcrack. $\Delta K_{\mathrm{I}}$ was then compared to the crack threshold. The crack size is initially very small, hence the small crack to long crack threshold transition need to be taken into account. The well known El Haddad small crack threshold model $[60,61]$ was used here, where the long crack threshold $\Delta K_{\text {th }}$ is the asymptotic limit. The typical hard steels for bearings and gears do not show very high threshold SIF range values. Glodež et al. [62] reported $\Delta K_{\mathrm{th}}=8.5 \mathrm{MPa} \sqrt{\mathrm{m}}$ for AISI 4130 flame hardened, while Kaneta et al. [22] reported the range $\Delta K_{\mathrm{th}}=3.0-7.5 \mathrm{MPa} \sqrt{\mathrm{m}}$ for typical bearing steels. The value for the threshold SIF range should be obtained for any steel at the specific surface treatment condition, and this is quite difficult from an experimental point of view. The Fig.9 shows the mode I SIF range compared to the threshold, assuming $\Delta K_{\text {th }}=7.0 \mathrm{MPa} \sqrt{\mathrm{m}}$, and the Fig.10 shows the SIFs history for $c=c_{\mathrm{p}}$ calculated with the weight function technique. It is clear that the SIF range is higher than the threshold, just after a certain crack length. This crack size is here defined as the critical propagation crack size $c_{\mathrm{p}}$. The logical conclusion is that the pressurization is not the reason of initiation, because it has an important role only when the crack reaches a certain size. The initiation of a microcrack up to $c_{\mathrm{p}}$ is still due to the cyclic shear stress. After reaching a size larger than $c_{\mathrm{p}}$, the pressurization causes the further propagation.

Different fatigue loading conditions have different trends of the load SIF versus small crack threshold. For 


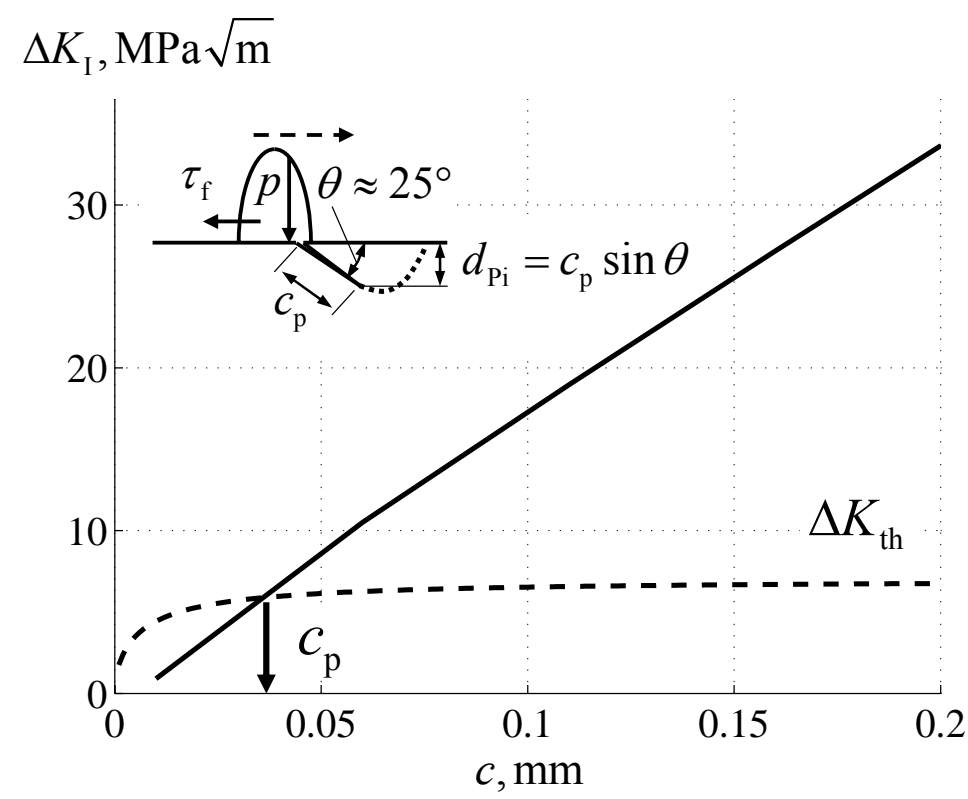

Figure 9: Mode I SIF range and threshold trends. Definition of the critical propagation crack size.

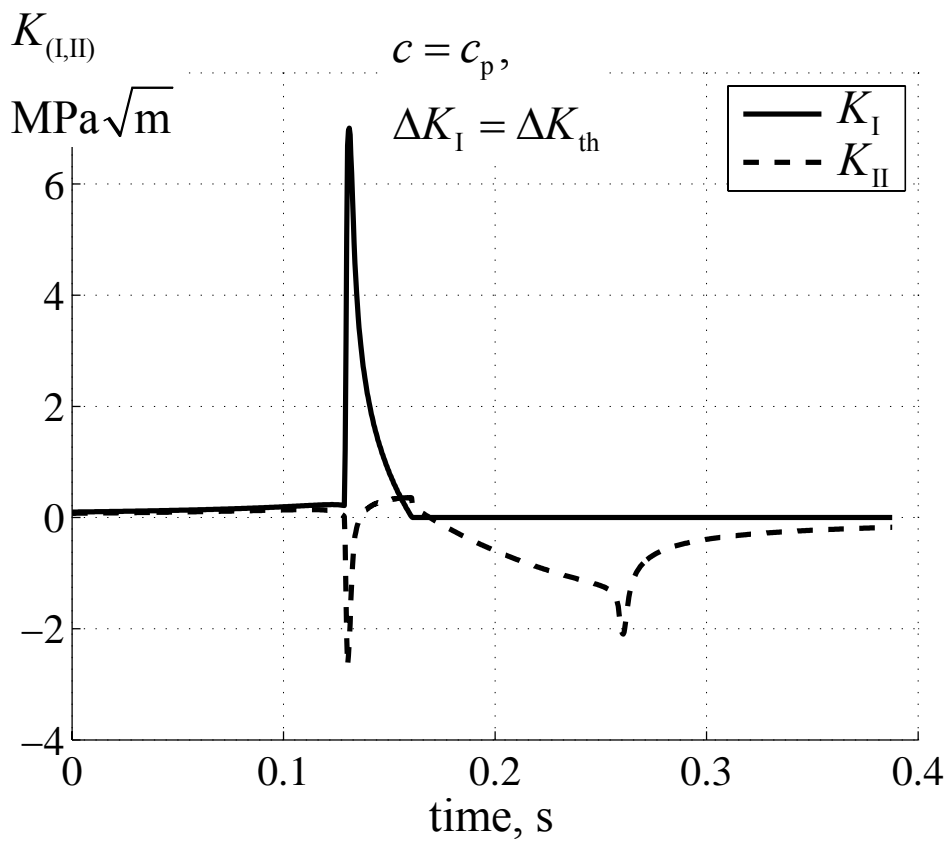

Figure 10: Mode I and mode II SIF histories for a crack size equal to the critical propagation crack length.

example, in fretting fatigue the peak tensile stress causes mode I SIF higher than the threshold even at small size of the crack, and the minimum difference between $\Delta K_{\mathrm{I}}$ and $\Delta K_{\text {th }}$ is reached at the El Haddad crack size itself [63, 64], eventually producing initiated non-propagating cracks for loading conditions below the fatigue limit. In that case the initiation is due to cyclic normal stress producing crack opening, while here the initiation can only be explained as cyclic shear stress.

According to Richard et al. [65], the fatigue crack propagation angle can be estimated from the $K_{\mathrm{I}}$ and $K_{\mathrm{II}}$ peak values during the fatigue cycle. The weight function approach allowed for the calculation of both $K_{\mathrm{I}}$ 


\begin{tabular}{lllll}
\hline Configuration & $R^{*}, \mathrm{~mm}$ & $p_{0}, \mathrm{MPa}$ & $f$ & Res. Stress, MPa \\
\hline $\mathrm{A}$ & 11.4 & 1600 & 0.05 & 0 \\
$\mathrm{~B}$ & 11.4 & 1600 & 0.05 & -800 \\
$\mathrm{C}$ & 22.8 & 1600 & 0.05 & 0 \\
$\mathrm{D}$ & 22.8 & 2000 & 0.05 & -800 \\
$\mathrm{E}$ & 22.8 & 1600 & 0.05 & -800 \\
$\mathrm{~F}$ & 45.5 & 1600 & 0.05 & -800 \\
\hline
\end{tabular}

Table 1: Data of the different load configurations reported in the Fig.11.

and $K_{\mathrm{II}}$ at different times, Fig.10, hence it was easy to determine the initial (predicted) propagation angle, after the critical crack size $c_{\mathrm{p}}$. It was found that the propagation angle typically ranges between $30^{\circ}$ and $35^{\circ}$ upward. According to this result, the pitting crack is suddenly driven toward the surface, because the initiated crack orientation angle is compensated by the onset propagation angle. The upward pitting crack path was also obtained as simulation result by Glodež et al. [62], and similar works, that always showed propagation toward the surface. This propagation orientation trend validates the claim that the initial surface microcrack is not produced by the repeated pressurization, otherwise the crack propagation would be upward and the pits shallower. A further remarkable result is that the final pitting crater can never be significantly deeper than the $c_{\mathrm{p}}$ vertical projection. This depth is here defined as the pitting (assisted by the pressurization) characteristic depth:

$$
d_{\mathrm{Pi}}=c_{\mathrm{p}} \sin \theta
$$

The angle $\theta$ is the surface crack orientation angle, that is almost coincident with the cyclic shear stress critical plane orientation angle, as mentioned before about micropitting, and it is about $25^{\circ}-30^{\circ}$ for a typical $f=0.05$ friction factor value.

The cyclic shear stress index, to characterize the fluid pressurization pitting, is formulated as the cyclic shear stress acting on the critical plane averaged over this pitting depth, Eq.6. This cyclic shear stress is the cause of a $c_{\mathrm{p}}$ crack onset while the pressurization mechanism is only reason of the further propagation.

$$
\Delta \tau_{\mathrm{Pi}}=\frac{1}{d_{\mathrm{Pi}}} \int_{0}^{d_{\mathrm{Pi}}} \Delta \tau(y) \mathrm{d} y
$$

The pitting depth $d_{\mathrm{Pi}}$ depends on several factors. $d_{\mathrm{Pi}}$ increases by introducing a compressive (negative) residual stress distribution, it also increases with higher equivalent radius of contact (size effect), and increases with lower contact pressure. Obviously $d_{\mathrm{Pi}}$ is also dependent on the material SIF threshold range: the lower the material threshold, the lower the pitting depth. A parametric investigation simulations was performed. Conditions investigated were: $\Delta K_{\mathrm{th}}=3-7 \mathrm{MPa} \sqrt{\mathrm{m}}$, residual stress $800 \mathrm{MPa}$ (compressive) or absent, equivalent radius of curvature $10-45 \mathrm{~mm}$, Hertz maximum contact pressure $p_{0}=1000-2000 \mathrm{MPa}$. The critical propagation crack sizes ranged between 10 and $80 \mu \mathrm{m}$, hence the pitting depth ranged between $4-34 \mu \mathrm{m}$. This parametric analysis is summarized in the Tab.1 and in the Fig.11.

The pressurization pitting depth $d_{\mathrm{Pi}}$ value can be very low, especially when the threshold is small, the Hertz pressure is high, and the equivalent radius of curvature is small. It is worth noting that these conditions actually are common in bearings and gears. The pitting depth value can be in the order of $10 \mu \mathrm{m}$, that is the micropitting depth, or even smaller. This means that the micropitting can be either surface microcracks originated without the pressurization effect, such as in gear addendum of the Fig.5, or supported by the lubricating fluid pressurization, when the $S / R$ is negative and the depth $d_{\mathrm{Pi}}$ value is small. In this latter case, the micropitting to deeper pitting distinction (Fig.4 scheme) does not apply. 


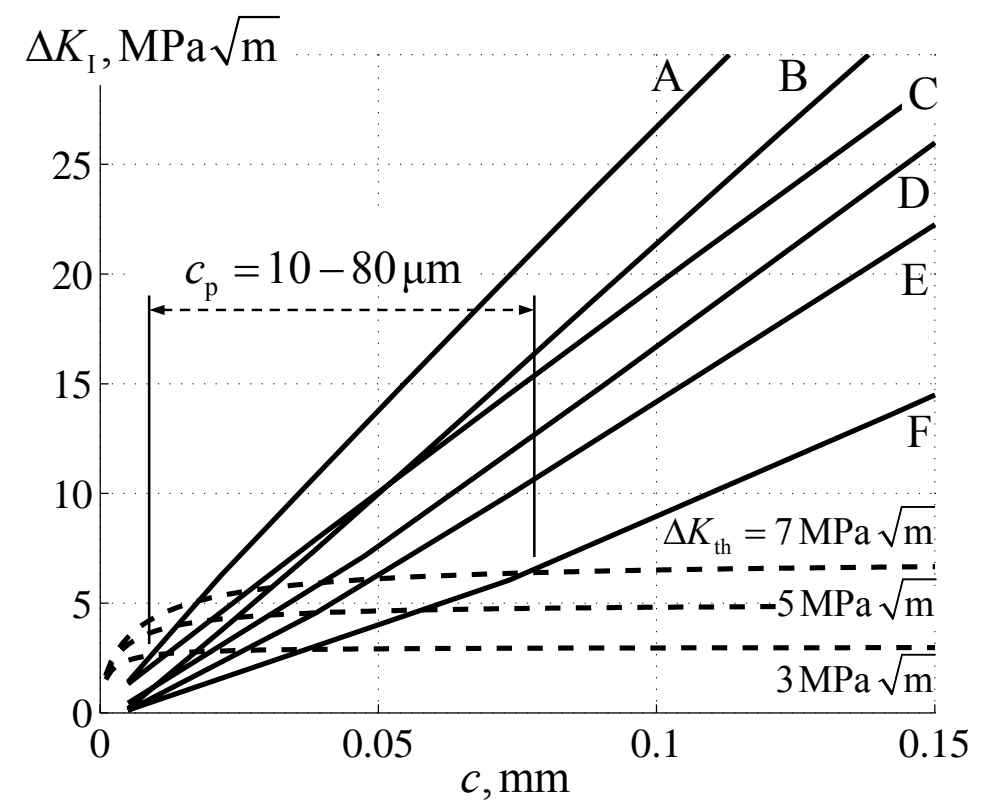

Figure 11: Wide range of critical propagation crack sizes.

\section{Characteristic depths validation and discussion}

\subsection{Subsurface spalling depth}

The present paper introduces as subsurface characteristic depth the position of the maximum cyclic shear stress. This is in agreement with the investigation by Chen et al. [18], they experimentally found that the position where the cyclic shear stress is maximum coincides with the location of the observed subsurface crack initiation. Nélias et al. [12] reported as an issue that maximum of the butterflies distribution, below the surface, is at a lower depth than the maximum shear stress position. It is worthy to be remarked that Nélias et al. [12] took into account the maximum shear stress below the surface, while Chen et al. [18] considered the maximum cyclic shear stress amplitude. Ding et al. $[8,9]$ reported that the spalling crater depth is approximately 0.35 times the half width of contact. This depth is shallower than the maximum cyclic shear stress position that is approximately at 0.5 times the half width of contact. Three tests are reported in the paper by Ding and Gear [9], at different Hertz contact pressures on a small gear set: $E=195000 \mathrm{MPa}, v=0.3, R^{*}=3.72 \mathrm{~mm}, f=0.06$. After subsurface investigation, they reported measured average spalling depths: $20 \mu \mathrm{m}$ with $p_{0}=898 \mathrm{MPa}$; $37 \mu \mathrm{m}$ with $p_{0}=1503 \mathrm{MPa} ; 52 \mu \mathrm{m}$ with $p_{0}=1885 \mathrm{MPa}$. According to the proposed investigation, the spalling depths are: $d_{\mathrm{Sp}}=31 \mu \mathrm{m}$ with $p_{0}=898 \mathrm{MPa} ; d_{\mathrm{Sp}}=52 \mu \mathrm{m}$ with $p_{0}=1503 \mathrm{MPa} ; d_{\mathrm{Sp}}=66 \mu \mathrm{m}$ with $p_{0}=1885 \mathrm{MPa}$. A likely explanation of these small depth differences could be the ligament theory, supported by Ding et al. themselves. The spalling crater is the result of the fracture of the weakest path between the initiated spalling crack population and the surface. The shallower initiated microcracks have shorter (and weaker) ligament. Moreover, it is worth noting that the cyclic shear stress is very near to the maximum in a quite large depth range before the $d_{\mathrm{Sp}}$, Fig.7(b). In conclusion, shallower cracks have a weaker ligament and experience only slightly lower cyclic shear.

An other test available in the literature was considered. The paper by Fajdiga et al. [10] reported an experimental evidence of a subsurface spall, and the load data of the experiment: Young's modulus $E=206000 \mathrm{MPa}$, Poisson ratio $v=0.3$, Hertz maximum contact pressure $p_{0}=1550 \mathrm{MPa}$, equivalent radius $R^{*}=10 \mathrm{~mm}$ (half width of contact $a=0.274 \mathrm{~mm}$ ), coefficient of friction $f=0.04$. The depth of the experimentally detected spall is $135 \mu \mathrm{m}$. This depth was found in excellent agreement with $d_{\mathrm{Sp}}=137 \mu \mathrm{m}$ obtained with the calculation proposed in the present paper. This depth prediction confirmed the good interpretation of the proposed 
analysis, while in the previous case the small size of the problem could have a role, promoting shallower spalling.

\subsection{Surface pitting depth}

A similar validation is also proposed for the Pitting characteristic depth. In the papers by Fajdiga et al. [54] and by Fajdiga and Sraml [39] an experiment on a carburized steel $16 \mathrm{MnCr} 5$ is reported. The typical surface pitting damage was showed, Fig.12, with the clear indication of $8 \mu \mathrm{m}$ depth.

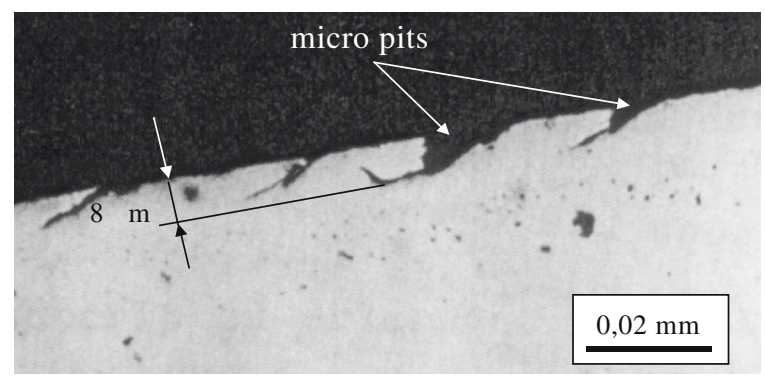

Figure 12: Evidence of pressurized lubricating fluid micropitting, after Fajdiga and Sraml [39] (republishing permission of this figure to be required).

Contact parameters of the present case study are: $E=206000 \mathrm{MPa}, v=0.3, p_{0}=1550 \mathrm{MPa}, R^{*}=10 \mathrm{~mm}$, $a=0.274 \mathrm{~mm}, f=0.04$ (same Hertz load of the previous spalling case). The estimated residual stress distribution, reported by Fajdiga et al. [54], was also introduced in the proposed calculation. The surface residual stress was $650 \mathrm{MPa}$ (compressive) with a small variation in the initial $0.1 \mathrm{~mm}$ depth. The long crack threshold stress intensity factor range $\Delta K_{\text {th }}$ is reason of discussion. The paper by Zafošnik et al. [66] reported $\Delta K_{\text {th }}=8.5 \mathrm{MPa} \sqrt{\mathrm{m}}$, same value reported by Glodež et al. [62], for the carburized steel $16 \mathrm{MnCr} 5$. This relatively high value can be questionable for the hardened steel layer, while it is a reasonable value for the bulk material. After introducing this quantity and performing the proposed calculation, the obtained Pitting depth was $d_{\mathrm{Pi}}=10.7 \mu \mathrm{m}$, that is already a fairly good approximation of the $8 \mu \mathrm{m}$ experimental evidence. If a lower threshold stress intensity factor range is introduced, a lower value is obtained. By introducing $\Delta K_{\mathrm{th}}=7.5 \mathrm{MPa} \sqrt{\mathrm{m}}$ (upper bound of the Kaneta range indication), $d_{\mathrm{Pi}}=10.0 \mu \mathrm{m}$ was obtained. Finally, with $\Delta K_{\mathrm{th}}=5.0 \mathrm{MPa} \sqrt{\mathrm{m}}$, the result obtained was $d_{\mathrm{Pi}}=8.1 \mu \mathrm{m}$, that is perfectly matching the experiment.

A remarkable result is that the Pitting depth can be as small as the Miropitting typical depth of $10 \mu \mathrm{m}$ or even smaller. As a consequence, observed craters deeper than $d_{\mathrm{Pi}}$ necessarily are subsurface initiated, instead of surface initiated. Moreover, the limited surface pitting depth may be the explanation of the "quiescent layer" concept, proposed in the literature as mentioned above. The surface initiated craters remain shallow because of the sudden upward propagation direction, caused by the pressurization, rather than a layer of lower cyclic stress.

\section{Application}

A numerical example is proposed here. The RCF depths and the stress indexes of two spur gear sets were calculated and compared. The two gear sets are largely different in size (main dimensions are reported in the Tab.2), while the torque loads were selected to have the same level of Hertz contact pressure, in order to highlight the size effects introduced above.

The pressure distribution was calculated at the Pitch Point (PP), at the Lowest Point of Single Tooth Contact (LPSTC) and at the Highest Point of Single Tooth Contact (HPSTC) along with the Hertz half width of contact a. $p_{\mathrm{P}}, p_{\mathrm{L}}, p_{\mathrm{H}}$ are the maximum pressure values at the PP, the LPSTC, and the HPSTC respectively. The values are reported in the Tab.3 for the low torque case (Torque 1) and in the Tab.4 for the high torque case (Torque 2). 


\begin{tabular}{lll}
\hline & $\begin{array}{l}\text { Small } \\
\text { gear set }\end{array}$ & $\begin{array}{l}\text { Large } \\
\text { gear set }\end{array}$ \\
\hline Teeth number, gear 1 & 20 & 40 \\
Teeth number, gear 2 & 20 & 40 \\
Module & $2 \mathrm{~mm}$ & $5 \mathrm{~mm}$ \\
Pressure angle & $20^{\circ}$ & $20^{\circ}$ \\
Addendum & $2 \mathrm{~mm}$ & $5 \mathrm{~mm}$ \\
Dedendum & $2.5 \mathrm{~mm}$ & $6.25 \mathrm{~mm}$ \\
Face width & $20 \mathrm{~mm}$ & $100 \mathrm{~mm}$ \\
Tip relief & $0.040 \mathrm{~mm}$ & $0.090 \mathrm{~mm}$ \\
Crowning & $0.010 \mathrm{~mm}$ & $0.050 \mathrm{~mm}$ \\
Torque 1 & $7.5 \mathrm{Nm}$ & $250 \mathrm{~N} \mathrm{~m}$ \\
Torque 2 & $69.6 \mathrm{Nm}$ & $9500 \mathrm{~N} \mathrm{~m}$ \\
\hline
\end{tabular}

Table 2: Different size gear sets: geometry data and loads.

The torque values were calibrated to have pressures approximately $1000 \mathrm{MPa}$ and $2000 \mathrm{MPa}$ for both the two gear sets. The RCF depths and stress indexes were calculated for all cases, assuming typical values: $f=0.05$, $\Delta K_{\mathrm{th}}=7.0 \mathrm{MPa} \sqrt{\mathrm{m}}, d_{\mathrm{CC}}=0.8 \mathrm{~mm}, d_{\mathrm{MP}}=10 \mu \mathrm{m}$. LPSTC and HPSTC are specular points since the numbers of teeth were chosen equal between the two gears of each gear set. The only difference is that the S/R is positive at the HPST, so the pressurization pitting parameters were not defined. The sliding at the pitch point is zero. A position slightly below the pitch (in the dedendum) was assumed, where the $S / R$ is negative. The main results of this comparison analysis are summarized in the following, and described in the Fig. 13.

- The case crushing stress index $\Delta \tau_{\mathrm{CC}}$ is much lower for the small gears than the larger gears, assuming same hardening depth $d_{\mathrm{CC}}$, being the size of the stressed region related to the contact width $a$, Fig.13(a).

- The subsurface spalling stress index $\Delta \tau_{\mathrm{Sp}}$ is just related to the contact pressure, hence it shows similar values for the two gear sets. The spalling depth $d_{\mathrm{Sp}}$ is proportional to the contact size, thus the smaller gear has a smaller depth of maximum $\Delta \tau$, Fig.13(a).

- The pressurization pitting depth $d_{\mathrm{Pi}}$ is also affected by the contact width, though less than proportional. The larger the contact width, the stronger the closure effect and then the higher the crack size to reach the threshold stress intensity factor range, Fig.13(b).

- The two surface mechanisms: pitting and micropitting, can not be distinguished for those cases where $d_{\mathrm{Pi}}$ is equal, or even smaller, than $d_{\mathrm{MP}}$. The unique surface damage is the pressurization pitting (that actually is "micro") and $d_{\mathrm{Pi}}$ and $\Delta \tau_{\mathrm{Pi}}$ can be considered only. 


\begin{tabular}{lll}
\hline & $\begin{array}{l}\text { Small } \\
\text { gear set }\end{array}$ & $\begin{array}{l}\text { Large } \\
\text { gear set }\end{array}$ \\
\hline \hline$p_{\mathrm{P}}$ & $920 \mathrm{MPa}$ & $915 \mathrm{MPa}$ \\
\hline$a$ & $0.056 \mathrm{~mm}$ & $0.278 \mathrm{~mm}$ \\
$\Delta \tau_{\mathrm{CC}}$ & $40 \mathrm{MPa}$ & $192 \mathrm{MPa}$ \\
$\Delta \tau_{\mathrm{Sp}}$ & $457 \mathrm{MPa}$ & $459 \mathrm{MPa}$ \\
$d_{\mathrm{Sp}}$ & $0.032 \mathrm{~mm}$ & $0.144 \mathrm{~mm}$ \\
$\Delta \tau_{\mathrm{Pi}}$ & $270 \mathrm{MPa}$ & $198 \mathrm{MPa}$ \\
$d_{\mathrm{Pi}}$ & $0.0080 \mathrm{~mm}$ & $0.0173 \mathrm{~mm}$ \\
$\Delta \tau_{\mathrm{MP}}$ & $292 \mathrm{MPa}$ & $164 \mathrm{MPa}$ \\
\hline \hline$p_{\mathrm{L}}$ & $930 \mathrm{MPa}$ & $920 \mathrm{MPa}$ \\
\hline$a$ & $0.054 \mathrm{~mm}$ & $0.278 \mathrm{~mm}$ \\
$\Delta \tau_{\mathrm{CC}}$ & $38 \mathrm{MPa}$ & $191 \mathrm{MPa}$ \\
$\Delta \tau_{\mathrm{Sp}}$ & $462 \mathrm{MPa}$ & $472 \mathrm{MPa}$ \\
$d_{\mathrm{Sp}}$ & $0.032 \mathrm{~mm}$ & $0.144 \mathrm{~mm}$ \\
$\Delta \tau_{\mathrm{Pi}}$ & $272 \mathrm{MPa}$ & $198 \mathrm{MPa}$ \\
$d_{\mathrm{Pi}}$ & $0.0077 \mathrm{~mm}$ & $0.0155 \mathrm{~mm}$ \\
$\Delta \tau_{\mathrm{MP}}$ & $298 \mathrm{MPa}$ & $171 \mathrm{MPa}$ \\
\hline \hline$p_{\mathrm{H}}$ & $930 \mathrm{MPa}$ & $920 \mathrm{MPa}$ \\
\hline$a$ & $0.054 \mathrm{~mm}$ & $0.278 \mathrm{~mm}$ \\
$\Delta \tau_{\mathrm{CC}}$ & $38 \mathrm{MPa}$ & $191 \mathrm{MPa}$ \\
$\Delta \tau_{\mathrm{Sp}}$ & $462 \mathrm{MPa}$ & $472 \mathrm{MPa}$ \\
$d_{\mathrm{Sp}}$ & $0.032 \mathrm{~mm}$ & $0.144 \mathrm{~mm}$ \\
$\Delta \tau_{\mathrm{Pi}}$ & $\mathrm{n} / \mathrm{a}$ & $\mathrm{n} / \mathrm{a}$ \\
$d_{\mathrm{Pi}}$ & $\mathrm{n} / \mathrm{a}$ & n/a \\
$\Delta \tau_{\mathrm{MP}}$ & $298 \mathrm{MPa}$ & $171 \mathrm{MPa}$ \\
\hline & &
\end{tabular}

Table 3: Torque 1 (contact pressure $1000 \mathrm{MPa}$ approximately) RCF depths and stress indexes.

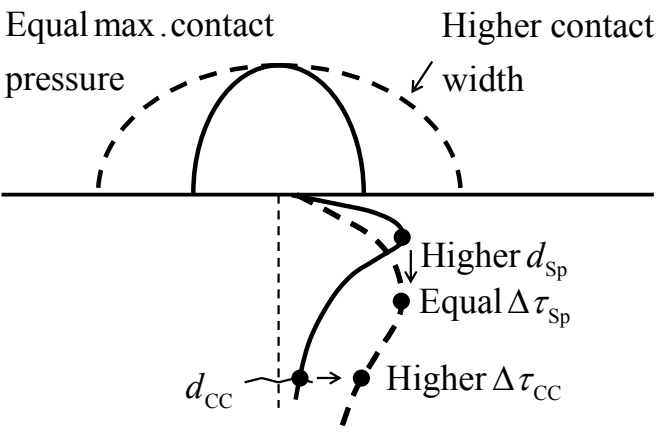

(a)

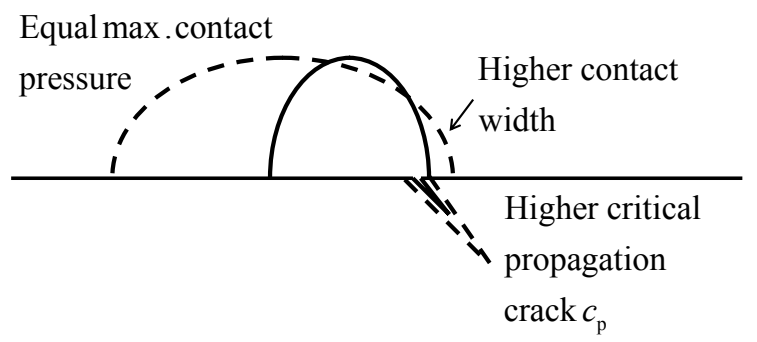

(b)

Figure 13: (a) Size effect on the subsurface mechanisms. (b) Size effect on the surface pitting critical propagation crack length.

\section{Conclusions}

The case crushing, spalling, pitting and micropitting mechanisms were distinguished and deeply described by reviewing the rolling contact fatigue literature. A cyclic shear stress index was defined for each rolling con- 


\begin{tabular}{lll}
\hline & $\begin{array}{l}\text { Small } \\
\text { gear set }\end{array}$ & $\begin{array}{l}\text { Large } \\
\text { gear set }\end{array}$ \\
\hline \hline$p_{\mathrm{P}}$ & $1820 \mathrm{MPa}$ & $1900 \mathrm{MPa}$ \\
\hline$a$ & $0.111 \mathrm{~mm}$ & $0.577 \mathrm{~mm}$ \\
$\Delta \tau_{\mathrm{CC}}$ & $159 \mathrm{MPa}$ & $691 \mathrm{MPa}$ \\
$\Delta \tau_{\mathrm{Sp}}$ & $911 \mathrm{MPa}$ & $954 \mathrm{MPa}$ \\
$d_{\mathrm{Sp}}$ & $0.053 \mathrm{~mm}$ & $0.288 \mathrm{~mm}$ \\
$\Delta \tau_{\mathrm{Pi}}$ & $367 \mathrm{MPa}$ & $297 \mathrm{MPa}$ \\
$d_{\mathrm{Pi}}$ & $0.0055 \mathrm{~mm}$ & $0.0115 \mathrm{~mm}$ \\
$\Delta \tau_{\mathrm{MP}}$ & $451 \mathrm{MPa}$ & $287 \mathrm{MPa}$ \\
\hline \hline$p_{\mathrm{L}}$ & $1850 \mathrm{MPa}$ & $1920 \mathrm{MPa}$ \\
\hline$a, \mathrm{~mm}$ & 0.108 & 0.581 \\
$\Delta \tau_{\mathrm{CC}}$ & $138 \mathrm{MPa}$ & $671 \mathrm{MPa}$ \\
$\Delta \tau_{\mathrm{Sp}}$ & $939 \mathrm{MPa}$ & $971 \mathrm{MPa}$ \\
$d_{\mathrm{Sp}}$ & $0.053 \mathrm{~mm}$ & $0.288 \mathrm{~mm}$ \\
$\Delta \tau_{\mathrm{Pi}}$ & $368 \mathrm{MPa}$ & $295 \mathrm{MPa}$ \\
$d_{\mathrm{Pi}}$ & $0.0050 \mathrm{~mm}$ & $0.0104 \mathrm{~mm}$ \\
$\Delta \tau_{\mathrm{MP}}$ & $469 \mathrm{MPa}$ & $292 \mathrm{MPa}$ \\
\hline \hline$p_{\mathrm{H}}$ & $1850 \mathrm{MPa}$ & $1920 \mathrm{MPa}$ \\
\hline$a, \mathrm{~mm}$ & 0.108 & 0.581 \\
$\Delta \tau_{\mathrm{CC}}$ & $138 \mathrm{MPa}$ & $671 \mathrm{MPa}$ \\
$\Delta \tau_{\mathrm{Sp}}$ & $939 \mathrm{MPa}$ & $971 \mathrm{MPa}$ \\
$d_{\mathrm{Sp}}$ & $0.053 \mathrm{~mm}$ & $0.288 \mathrm{~mm}$ \\
$\Delta \tau_{\mathrm{Pi}}$ & $\mathrm{n} / \mathrm{a}$ & $\mathrm{n} / \mathrm{a}$ \\
$d_{\mathrm{Pi}}$ & n/a & n/a \\
$\Delta \tau_{\mathrm{MP}}$ & $469 \mathrm{MPa}$ & $292 \mathrm{MPa}$ \\
\hline & &
\end{tabular}

Table 4: Torque 2 (contact pressure $2000 \mathrm{MPa}$ approximately) RCF depths and stress indexes.

tact fatigue mechanism, and this required the introduction of a characteristic depth, that identifies the process zone. Specific laboratory tests can be related to the component design, by reproducing both the stress index and the size, identified by the characteristic depths. Moreover, the penetration of any surface treatment can be optimized on the basis of these depths, rather than empirical methods.

The cyclic shear stress critical plane is almost horizontal below the surfac, while it is inclined by a shallow angle (depending on the friction coefficient) at the surface. The surface critical plane angle was found in excellent agreement with the experimental evidence of the surface microcrack orientation, supporting the cyclic shear stress initiation. The fluid pressurization can not be the reason of the surface microcrack initiation, because the positive stress intensity factor range, produced by the fluid pressurization, is above the threshold only after a certain crack size. The initial shallow angle is suddenly compensated by the onset crack propagation angle, thus the surface crack propagates upward generating the typical pitting small craters, without any further depth increment. Subsurface spalling and surface pitting depths were validated on the basis of literature data. This validation showed slightly overestimation for small size gear subsurface depths, while accurate prediction was obtained for larger contact size. The surface pitting depth depends on the material threshold stress intensity factor. An accurate validation result was obtained with a proper assessment of the threshold. The surface pitting depth also depends on the size of contact and on the pressure load. Heavily loaded and small radius contacts generate very small pitting depths, that can be as small as the typical $10 \mu \mathrm{m}$ micropitting depth, or even smaller. Pitting and micropitting can be no more distinguished under these contact conditions, that are quite common in high performance bearings and gears. 


\section{Acknowledgments}

AVIO Propulsione Aerospaziale S.p.A. company is acknowledged by the authors for supporting the research published in the present paper.

\section{References}

[1] A.V. Olver. The mechanism of rolling contact fatigue: an update. Proceedings of the Institution of Mechanical Engineers, Part J: Journal of Engineering Tribology, 219(5):313-330, 2005.

[2] F. Sadeghi, B. Jalalahmadi, T.S. Slack, N. Raje, and N.K. Arakere. A Review of Rolling Contact Fatigue. Journal of Tribology , ASME, 131(4):041403-1-15, 2009.

[3] U. Zerbst, R. Lundén, K.O. Edel, and R.A. Smith. Introduction to the damage tolerance behaviour of railway rails - a review. Engineering Fracture Mechanics, 76(17):2563-2601, 2009.

[4] D.P. Townsend. Dudley's Gear Handbook. McGraw-Hill, 2nd edition, 1991.

[5] T.E. Tallian. Failure Atlas for Hertz Contact Machine Elements. ASME Press, 1992.

[6] T.E. Tallian, Y.P. Chiu, and E. Van Amerongen. Prediction of traction and microgeometry effects on rolling contact fatigue life. Journal of Lubrication Technology, ASME, 100:156-160, 1978.

[7] W.E. Littmann. The mechanism of contact fatigue. In P.M. Ku, editor, Interdisciplinary approach to the lubrication of concentrated contacts, 1969. Troy, NY. NASA Special Report SP-237, 1970, p.309-378.

[8] Y. Ding and N.F. Rieger. Spalling formation mechanism for gears. Wear, 254(12):1307-1317, 2003.

[9] Y. Ding and J.A. Gear. Spalling depth prediction model. Wear, 267(5-8):1181-1190, 2009.

[10] G. Fajdiga, S. Glodež, and J. Kramar. Pitting formation due to surface and subsurface initiated fatigue crack growth in contacting mechanical elements. Wear, 262(9-10):1217-1224, 2007.

[11] S. Glodež, J. Flažsker, and Z. Ren. A new model for the numerical determination of pitting resistance of gear teeth flanks. Fatigue \& Fracture of Engineering Materials \& Structures, 20(1):71-83, 1997.

[12] D. Nélias, M.L. Dumont, F. Champiot, A. Vincent, and D. Girodin. Role of Inclusions, Surface Roughness and Operating Conditions on Rolling Contact Fatigue. Journal of Tribology, ASME, 121(2):240$251,1999$.

[13] D. Nélias, M.L. Dumont, F. Couhier, G. Dudragne, and L. Flamand. Experimental and Theoretical Investigation on Rolling Contact Fatigue of 52100 and M50 Steels Under EHL or Micro-EHL Conditions. Journal of Tribology, ASME, 120(2):184-200, 1998.

[14] Y.K. Gao. Influence of Deep-Nitriding and Shot Peening on Rolling Contact Fatigue Performance of 32Cr3MoVA Steel. Journal of Materials Engineering and Performance, 17(4):455-459, 2008.

[15] G.P. Cavallaro, T.P. Wilks, C. Subramanian, K.N. Strafford, P. French, and J.E. Allison. Bending fatigue and contact fatigue characteristics of carburized gears. Surface and Coatings Technology, 71(2):182-192, 1995.

[16] A. Vincent, G. Lormand, P. Lamagnere, L. Gosset, D. Girodin, G. Dudragne, and R. Fougères. From white etching areas formed around inclusions to crack nucleation in bearing steels under rolling contact fatigue. In Bearing Steel into the 21st Century, pages 109-123. ASTM STP 1327, 1997. 
[17] H. Schlicht, E. Schreiber, and O. Zwirlein. Effects of Material Properties on Bearing Steel Fatigue Strength. In J.C.C. Hoo, editor, Effects of Steel Manufacturing Processes on the Quality of Bearing Steels, pages 81-101. ASTM STP 987, 1988. ASTM Special Technical Pubication, Philadelphia, PA.

[18] L. Chen, Q. Chen, and E. Shao. Study on initiation and propagation angles of subsurface cracks in GCr15 bearing steel under rolling contact. Wear, 133(2):205-218, 1989.

[19] J.R. Fleming and N.P. Suh. Mechanics of crack propagation in delamination wear. Wear, 44(1):39-56, 1977.

[20] L.M. Keer and M.D. Bryant. A pitting model for rolling contact fatigue. Journal of Lubrication Technology, ASME, 105:198-205, 1983.

[21] S.D. O'regan, G.T. Hahn, and C.A. Rubin. The driving force for mode II crack growth under rolling contact. Wear, 101(4):333-346, 1985.

[22] M. Kaneta, Y. Murakami, and T. Okazaki. Growth Mechanism of Subsurface Crack Due to Hertzian Contact. Journal of Tribology, ASME, 108(1):134-139, 1986.

[23] J.W. Blake and H.S. Cheng. A Surface Pitting Life Model for Spur Gears: Part I-Life Prediction. Journal of Tribology, ASME, 113(4):712-718, 1991.

[24] Y. Choi and C.R. Liu. Rolling contact fatigue life of finish hard machined surfaces: Part 1. Model development. Wear, 261(5-6):485-491, 2006.

[25] Y. Choi and C.R. Liu. Spall progression life model for rolling contact verified by finish hard machined surfaces. Wear, 262(1-2):24-35, 2007.

[26] Y. Choi. Influence of tool flank wear on performance of finish hard machined surfaces in rolling contact. International Journal of Fatigue, 32(2):390-397, 2010.

[27] Y. Ding, R. Jones, and B. Kuhnell. Numerical analysis of subsurface crack failure beneath the pitch line of a gear tooth during engagement. Wear, 185(1-2):141-149, 1995.

[28] Y. Ding, R. Jones, and B.T. Kuhnell. Elastic-plastic finite element analysis of spall formation in gears. Wear, 197(1-2):197-205, 1996.

[29] S. Glodež, H. Winter, and H. P. Stüwe. A fracture mechanics model for the wear of gear flanks by pitting. Wear, 208(1-2):177-183, 1997.

[30] S. Glodež, Z. Ren, and J. Flašker. Simulation of surface pitting due to contact loading. International Journal for Numerical Methods in Engineering, 43(1):33-50, 1998.

[31] V.V. Panasyuk, O.P. Datsyshyn, and H.P. Marchenko. The crack propagation theory under rolling contact. Engineering Fracture Mechanics, 52(1):179-191, 1995.

[32] N. Raje and R.G. Rateick. A Statistical Damage Mechanics Model for Subsurface Initiated Spalling in Rolling Contacts. Journal of Tribology, ASME, 130(4):042201-1-11, 2008.

[33] N. Raje, T. Slack, and F. Sadeghi. A discrete damage mechanics model for high cycle fatigue in polycrystalline materials subject to rolling contact. International Journal of Fatigue, 31(2):346-360, 2009.

[34] M. Boniardi, F. D'Errico, and C. Tagliabue. Influence of carburizing and nitriding on failure of gears A case study. Engineering Failure Analysis, 13(3):312-339, 2006. 
[35] X. Leng, Q. Chen, and E. Shao. Initiation and propagation of case crushing cracks in rolling contact fatigue. Wear, 122(1):33-43, 1988.

[36] Q. Chen, X. Leng, and E. Shao. Influence of microstructure and residual stress on the stages of case crushing. Wear, 122(1):45-55, 1988.

[37] A.V. Olver, L.K. Tiew, S. Medina, and J.W. Choo. Direct observations of a micropit in an elastohydrodynamic contact. Wear, 256(1-2):168-175, 2004.

[38] S. Glodež, Z. Ren, and G. Fajdiga. Computational modelling of the surface fatigue crack growth on gear teeth flanks. Communications in Numerical Methods in Engineering, 17(8):529-541, 2001.

[39] G. Fajdiga and M. Sraml. Fatigue crack initiation and propagation under cyclic contact loading. Engineering Fracture Mechanics, 76(9):1320-1335, 2009.

[40] G.R. Miller, L.M. Keer, and H.S. Cheng. On the mechanics of fatigue crack growth due to contact loading. In Proceedings of the Royal Society A, volume 397, pages 197-289, 1985.

[41] G. Donzella and C. Petrogalli. A failure assessment diagram for components subjected to rolling contact loading. International Journal of Fatigue, 32(2):256-268, 2010.

[42] A.F. Bower. The Influence of Crack Face Friction and Trapped Fluid on Surface Initiated Rolling Contact Fatigue Cracks. Journal of Tribology, ASME, 110(4):704-711, 1988.

[43] S. Way. Pitting due to rolling contact. Journal of Applied Mechanics, ASME, 57:A49-A58, 1935.

[44] K.L. Johnson. The strength of surfaces in rolling contact. In Journal of Mechanical Engineering Science, editor, Proceedings of the Institution of Mechanical Engineers, volume 203, pages 151-163, 1989.

[45] O.P. Datsyshyn and H.P. Marchenko. Stressed state of a half plane with shallow edge crack under hertzian loading (a survey). Materials Science, 44(1):22-34, 2008.

[46] X. Jin, L.M. Keer, and E.L. Chez. Numerical simulation of growth pattern of a fluid-filled subsurface crack under moving hertzian loading. International Journal of Fracture, 142(3-4):219-232, 2006.

[47] Y. Murakami, C. Sakae, K. Ichimaru, and T. Morita. Experimental and Fracture Mechanics Study of the Pit Formation Mechanism Under Repeated Lubricated Rolling-Sliding Contact: Effects of Reversal of Rotation and Change of the Driving Roller. Journal of Tribology, ASME, 119(4):846-850, 1997.

[48] O.P. Datsyshyn and A.B. Levus. Propagation of an edge crack under the pressure of liquid in the vicinity of the crack tip. Materials Science, 39(5):754-757, 2003.

[49] A.C. Batista and A.M. Dias. Contact fatigue of carbonitrided and shot-peened gears. Effects of residual stresses. In GEARS \& TRANSMISSION Workshop, 2003.

[50] D.F. Socie and G.B. Marquis. Multiaxial Fatigue. SAE International, 1999.

[51] H.P. Evans, R.W. Snidle, and K.J. Sharif. Deterministic mixed lubrication modelling using roughness measurements in gear applications. Tribology International, 42(10):1406-1417, 2009.

[52] G. Lundberg and A. Palmgren. Dynamic capacity of rolling bearings. Acta Polytechnica Scandinavica. Mechanical Engineering Series, 1(3):1-52, 1947.

[53] G. Lundberg and A. Palmgren. Dynamic capacity of rolling bearings. Acta Polytechnica Scandinavica. Mechanical Engineering Series, 2(4):96-127, 1952. 
[54] G. Fajdiga, J. Flašker, S. Glodež, and T.K. Hellen. Numerical modelling of micro-pitting of gear teeth flanks. Fatigue \& Fracture of Engineering Materials \& Structures, 26(12):1135-1143, 2003.

[55] J.W. Ringsberg and A. Bergkvist. On propagation of short rolling contact fatigue cracks. Fatigue \& Fracture of Engineering Materials \& Structures, 26(10):969-983, 2003.

[56] M. Beghini, L. Bertini, and V. Fontanari. Weight function for an inclined edge crack in a semiplane. International Journal of Fracture, 99(4):281-292, 1999.

[57] M. Beghini, L. Bertini, and V. Fontanari. Stress intensity factors for an inclined edge crack in a semiplane. Engineering Fracture Mechanics, 62(6):607-613, 1999.

[58] M. Beghini, L. Bertini, and V. Fontanari. A weight function technique for partially closed inclined edge cracks analysis. International Journal of Fracture, 112(1):57-68, 2001.

[59] M. Beghini and C. Santus. Application of the weight function technique for evaluating inclined surface crack under rolling contact fatigue: assessment and parametric analysis. Engineering Fracture Mechanics, 2012. Submitted.

[60] S. Suresh. Fatigue of Materials. Cambridge University Press, 2nd edition, 1998.

[61] D. Taylor. The Theory of Critical Distances: A New Perspective in Fracture Mechanics. Elsevier Science, 1 st edition, 2007.

[62] S. Glodež, R. Potočnik, J. Flašker, and B. Zafošnik. Numerical modelling of crack path in the lubricated rolling-sliding contact problems. Engineering Fracture Mechanics, 75(3-4):880-891, 2008.

[63] J.A. Araújo and Nowell. Analysis of pad size effects in fretting fatigue using short crack arrest methodologies. International Journal of Fatigue, 21(9):947-956, 1999.

[64] D. Dini, D. Nowell, and I.N. Dyson. The use of notch and short crack approaches to fretting fatigue threshold prediction: Theory and experimental validation. Tribology International, 39(10):1158-1165, 2006.

[65] H.A. Richard, M. Fulland, and M. Sander. Theoretical crack path prediction. Fatigue \& Fracture of Engineering Materials \& Structures, 28(1-2):3-12, 2005.

[66] B. Zafošnik, Z. Ren, J. Flašker, and G. Mishuris. Modelling of Surface Crack Growth under Lubricated Rolling-Sliding Contact Loading. International Journal of Fracture, 134(2):127-149, 2005. 